\title{
Study on Relationship of Segmental Distribution of Coronary Artery Disease and Peripheral Arterial Disease
}

\author{
S M AHSAN HABIB, MD. NAZMUL HASAN, A K M FAZLUR RAHMAN, MURSHED AHMED, NILUFAR FATEMA, \\ MANZOOR MAHMOOD, TANZIMA PARVIN, MD. MASHIULALAM, MD. NOORNABI, MOHAMMAD SAFIUDDIN, \\ MD ABU SIDDIQUE, SAJAL KRISHNA BANERJEE, NAZRUL ISLAM, MA MUQUEET \\ Department of Cardiology, Bangabandhu Sheikh Mujib Medical University (BSMMU), Dhaka, Bangladesh \\ Address for Correspondence: Dr S M Ahsan Habib. Associate Professor of Cardiology, Bangabandhu Sheikh Mujib Medical \\ University (BSMMU), Shahbag, Dhaka, Bangladesh. Email: drsmahsanhabib2015@gmail.com
}

\begin{abstract}
:
Objectives: The purpose of this study was to investigate pattern and involvement of peripheral artery disease of lower limbs in patients suffering from clinically significant coronary artery disease.

Methods: Total 58 patients with clinically diagnosed peripheral arterial disease of lower limb undergoing angiographic evaluation. Selective CAG in addition to peripheral arteriography was performed in all the study population as per ACC/AHA guidelines for CAG (class IIa recommendation).

Result: In this study, It was found that the proportion of aorto-iliac disease was higher among the patients with coronary arterial disease (77.8\%) and the association was statistically significant $(p<0.05)$. Analysis found no statistically significant association between coronary arterial disease and Femo-popliteal and tibioperoneal vascular disease $(p>0.05)$.

Conclusion: Patients of coronary artery disease (CAD) are more likely to have severe peripheral arterial disease (PAD) involvement. Peripheral angiogram is useful tool in patient with CAD to detect previously undetected $P A D$ and pattern of $C A D$ reflects the severity and involvement of peripheral arteries.
\end{abstract}

Key words: Peripheral arterial disease, coronary arteries.

Introduction:

The term peripheral arterial disease (PAD) generally refers to atherosclerotic vascular disease when it obstructs the blood supply to the lower or upper extremities ${ }^{1}$.Despite impressive strides in diagnosis and management over the past decades, PAD is one of the important public health problems both for the affluent and developing societies. PAD is a common vascular disease causing morbidity and mortality. Presence of PAD is a marker for underlying coronary artery disease (CAD).$^{2}$

PAD is a powerful indicator of systemic atherothrombotic disease. Regardless of whether symptoms are evident, patients with PAD have an increased risk of subsequent myocardial infarction and stroke. Symptomatic PAD are also at higher risk for developing chronic angina and are more likely to die from cardiovascular disease (CVD) . ${ }^{3}$

Several studies have been done regarding "Coronary artery involvement in patients undergoing angiographic evaluation of PAD" abroad. But no such study has been done in our country. Few studies have been conducted in our country regarding relation with $\mathrm{CAD} \&$ atherosclerotic carotid artery stenosis. But no study have been conducted regarding relation between atherosclerotic PAD of lower limbs and coronary artery disease. ${ }^{4,5}$
Method:

Total 58 patients with clinically diagnosed peripheral arterial disease of lower limb undergoing angiographic evaluation. Selective CAG in addition to peripheral arteriography was performed in all the study population as per ACC/AHA guidelines for $\mathrm{CAG}$ (class IIa recommendation).

After angiography patient population were divided into 3 groups based on CAG findings.

Group I- No coronary artery disease, Group II- Insignificant coronary artery disease (CAD),i.e. LM $<50 \%$ stenosis, others $<70 \%$ stenosis.Group III- Significant coronary artery disease (CAD),i.e. LMe" $50 \%$ stenosis, otherse" 70\% stenosis. Group II and group III patients were further divided into following subgroups according to number of vessel(s) involved - LMD (Left Main Disease),SVD (Single Vessel Disease),DVD (Double Vessel Disease),TVD (Triple Vessel Disease).

Peripheral angiographic patterns were classified into three groups depending upon segmental distribution : Aortoiliac - the lesion(s) may remain either in the abdominal aorta or iliac artery (both or individual) or any combination of them, Femoropopliteal - the lesion(s) may remain either in the 
both or individual (right/left) femoral or popliteal artery or any combination of them. Tibioperoneal - the lesion(s) may remain either in the both or individual (right/left) tibial or peroneal artery or any combination of them. Age below 40 years and Patients with suspected systemic vasculitis were excluded from the study.

\section{Statistical Analysis:}

Data were expressed in frequency, percentage, mean and standard deviation as applicable. Comparison between groups was done by unpaired student's t test, chi-square test, and Fisher's Exact test as applicable. Analysis of data was done by using computer based SPSS program (version 11.5). Probability less than 0.05 was considered as significant.

\section{Result:}

In this study, It was found that the proportion of aortoiliac disease was higher among the patients with coronary arterial disease $(77.8 \%)$ and the association was statistically significant $(\mathrm{p}<0.05)$. Analysis found no statistically significant association between coronary arterial disease and Femo-popliteal and tibioperoneal vascular disease $(p>0.05)$. The findings of the study obtained from data analyses are documented below:

Table-I

Distribution of patients by their baseline characteristics

\begin{tabular}{|c|c|c|c|c|c|c|c|}
\hline \multirow[t]{3}{*}{ Age in years } & \multicolumn{4}{|c|}{ Sex } & \multicolumn{2}{|c|}{ Total } & \multirow[t]{3}{*}{$*_{p}$ value } \\
\hline & \multicolumn{2}{|c|}{ Male } & \multicolumn{2}{|c|}{ Female } & & & \\
\hline & No. & $\%$ & No. & $\%$ & No. & $\%$ & \\
\hline $40-49$ & 18 & 34.6 & 2 & 33.3 & 20 & 34.5 & \\
\hline $50-59$ & 23 & 44.2 & 1 & 16.7 & 24 & 41.4 & \\
\hline $60+$ & 11 & 21.2 & 3 & 50.0 & 14 & 24.1 & \\
\hline Total & 52 & 100.0 & 6 & 100.0 & 58 & 100.0 & \\
\hline Mean \pm SD & \multicolumn{2}{|c|}{$53.0 \pm 7.4$} & \multicolumn{2}{|c|}{$56.3 \pm 12.1$} & \multicolumn{2}{|c|}{$53.3 \pm 7.9$} & \\
\hline Range & \multicolumn{2}{|c|}{$40-75$} & \multicolumn{2}{|c|}{$40-70$} & \multicolumn{2}{|c|}{$40-75$} & 0.331 \\
\hline
\end{tabular}

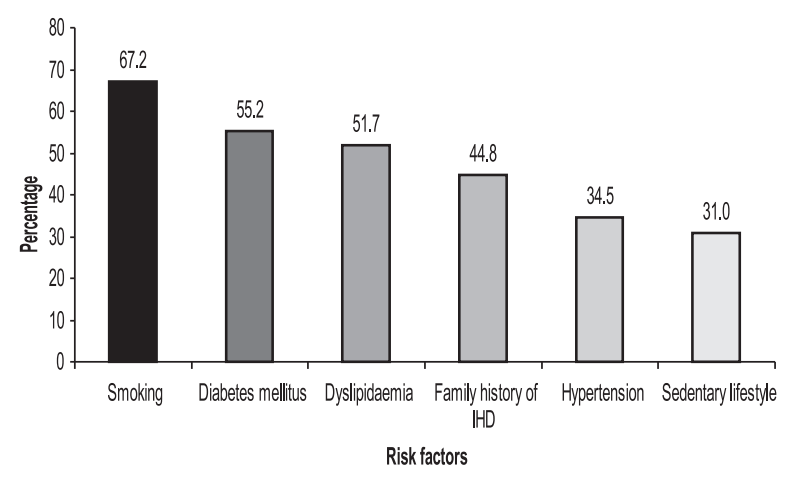

Fig.-I: Distribution of patients by risk factors $(n=58)$

Table-II

Segmental distribution of coronary artery disease and peripheral arterial disease

\begin{tabular}{|c|c|c|c|c|c|c|c|c|c|c|c|c|}
\hline & \multicolumn{4}{|c|}{ Aorto-iliac } & \multicolumn{4}{|c|}{ Femoropopliteal } & \multicolumn{4}{|c|}{ Tibioperoneal } \\
\hline & \multicolumn{2}{|c|}{ No disease } & \multicolumn{2}{|c|}{ Yes } & \multicolumn{2}{|c|}{ No disease } & \multicolumn{2}{|c|}{ Yes } & \multicolumn{2}{|c|}{ No disease } & \multicolumn{2}{|c|}{ Yes } \\
\hline & No. & $\%$ & $\overline{\text { No. }}$ & $\%$ & No. & $\%$ & No. & $\%$ & No. & $\%$ & No. & $\%$ \\
\hline Group I & 16 & 72.7 & 8 & 22.2 & 9 & 33.3 & 15 & 48.4 & 17 & 36.2 & 7 & 63.6 \\
\hline Group II & 2 & 9.1 & 7 & 19.4 & 6 & 22.2 & 3 & 9.7 & 8 & 17.0 & 1 & 9.1 \\
\hline Group III & 4 & 18.2 & 21 & 58.3 & 12 & 44.4 & 13 & 41.9 & 22 & 46.8 & 3 & 27.3 \\
\hline Total & 22 & 100.0 & 36 & 100.0 & 27 & 100.0 & 31 & 100.0 & 47 & 100.0 & 11 & 100.0 \\
\hline${ }^{*} p$ value & & & & & & 0.3 & & & & 0.2 & & \\
\hline
\end{tabular}




\section{Discussion:}

Among the 58 patients included in the study 52 were male and 6 were female. It shows that small number of female patients with PAD of lower limbs attended the hospital for treatment. So, this finding has no epidemiological implications.

The age of the patients ranged from 40 years to 75 years and mean age $53.3 \pm 7.9$ years. The mean age of group I, group II and group III were $50.0 \pm 6.3$ years, $55.3 \pm 11.9$ years and $55.8 \pm 6.7$ years respectively. So, statistically significant mean age difference was found between group III and group I patients $(\mathrm{P}<0.05)$. This indicates that significant coronary artery disease resulted in older age group. Similar age incidence of ischaemic heart disease was reported in the past study by different authors $6,7,8$. Hertzer et al. (1984), revealed that one third of the patients with coronary artery disease were less than 60 years of age and two third of patients were aged 60 years or above. ${ }^{9}$

Smoking was found as the most common risk factors $(67.2 \%)$, followed by diabetes mellitus $(55.2 \%)$, dyslipidemea (51.7\%), family history of IHD (44.8\%), hypertension (34.5\%) and sedentary life style (31\%). Hertzer et al. (1984) found that $25 \%$ of the patients with peripheral vascular disease were diabetic and $50 \%$ were hypertensive. ${ }^{9}$ Hirsch et al. (2001) showed that diabetes and hypertension were strongly related with peripheral vascular disease (Belch et al. 2003) ${ }^{10}$. Farkouh et al. (1994) showed that smoking and diabetes were significantly associated with peripheral vascular disease. ${ }^{11}$

Data analysis revealed that the proportion of smoking, diabetes mellitus, dyslipidemia, family history of IHD, hypertension and sedentary life style was significantly higher in patients with CAD than non CAD. This is consistent with the study of Balasubramanian et al. (2004) in which it was found that in patients with peripheral vascular disease, coronary artery disease was associated with hypertension, smoking and dyslipidaemia. ${ }^{2}$

Among the patients with coronary artery disease, $7.69 \%$ patients had left main (LM), 32.47\% had left anterior descending (LAD), 31.62\% had left circumflex (LCX) and $28.2 \%$ had right coronary artery (RCA) involvement. Hertzer et al (1984) showed that significant reduction of lumen diameter (stenosis $>50 \%$ ) in patient with lower extremity ischemia involved the RCA 40\%, LM 3.4\%, LAD $26 \%$ and LCX $30 \%{ }^{9}$

\section{Conclusion:}

Patients of coronary artery disease (CAD) are more likely to have severe peripheral arterial disease (PAD) involvement. Peripheral angiogram is useful tool in patient with CAD to detect previously undetected PAD and pattern of CAD reflects the severity and involvement of peripheral arteries.

\section{References:}

1. Creager, M.A., Libby P. 'Peripheral arterial disease', in A text book of cardiovascular medicine, $6^{\text {th }}$ ed. Braunwald, Zipes and Libby, W.B. Saunder's, Philadelphia, 2001; pp.1451-78.

2. Balasubramanian, S., Murugan, S., Amuthan, R.V. et al. 'Prevalence of coronary artery disease in symptomatic peripheral arterial disease', Indian Heart Journal, 2004;56(5): p.543.

3. Belch, J.F., Eric, J., Topol, et al. 'Critical issues in peripheral arterial disease detection and management', Arch Intern Med, 2003;163:884-92.

4. Bidhan, C.G. 2003, 'Correlation between carotid Atherosclerosis and coronary artery disease in patients with ischaemic heart disease', MD thesis, Bangabandhu Sheik Mujib Medical University of Dhaka.

5. Bari, M.S. 1998, 'Association of carotid artery atherosclerosis with coronary artery disease', MD thesis, University of Dhaka.

6. Malik, A., Islam, M.N., Zafar, A., Khan, A.K., Ramizuddin, M. 'Clinical pattern of ischaemic heart disease and its association with some known risk factors', Bangladesh Heart Journal, 1987;2:1-9.

7. Akanda, M.A.K. 1996, 'Correlation of the major coronary artery disease risk factors with the severity of coronary arterial lesions', MD thesis, University of Dhaka.

8. Kabir, H. 1999, 'Correlation between ECG and CAG findings in patients presenting with primary unstable angina', MD thesis, University of Dhaka.

9. Hertzer, N.R. 'Basic data concerning associated coronary disease in peripherals vascular patients', Ann Vasc. Surg, 1987;1:616-20.

10. Hirsch, A.T., Criqui, M.H., Treat, J.D. et al. 'Peripheral arterial disease detection, awareness, and treatment in primary care', JAMA, 2001;286:1317-24.

11. Michael, E., Farkouh, Charanjit, S., Rihal, et al. 'Influence of coronary heart disease on morbidity and mortality after lower extremity revascularization surgery; A population based study in Olmsted country, Minnesota (1970-1987)', $J$ Am Coll Cardiol, 1994;24:1290-96. 